\title{
Research on Flipped Classroom Teaching Mode of High School Mathematics under the Background of "Internet+"
}

\author{
Fenghan Chen \\ School of mathematical sciences \\ University of Jinan \\ Jinan, China
}

\author{
Fengtong Wen* \\ School of mathematical sciences \\ University of Jinan \\ Jinan, China
}

\begin{abstract}
In order to improve students' autonomous learning ability, they should start by changing the classroom teaching mode. Under the background of "Internet +", the new teaching mode of "flipped classroom" breaks the traditional teaching mode and teaches in the way of "learning before teaching, learning after teaching" to stimulate students' interest in learning and motivate students to learn. So it is of great significance to change traditional teaching methods and effectively introduce flipped classroom teaching mode in high school mathematics teaching. In this paper, taking the hyperbola and its standard equation in high school mathematics as an example, they carry out teaching design according to flipped classroom teaching mode. It can realize the organic combination of theory and practice by studying specific cases and provide practical experience for the effective implementation of the flipped classroom teaching model in the high school mathematics classroom.
\end{abstract}

Keywords-“Internet+"; flipped classroom; high school mathematics; case study

\section{INTRODUCTION}

With the development of science and technology, information technology has penetrated into all walks of life and changed people's traditional way of life. In the field of education, the Internet era has promoted educational reforms in the context of "Internet +". Flipped classroom teaching mode is an emerging teaching mode that meets the requirements of current education reform under the background of "Internet +", which fully embodies the teaching philosophy of "student-oriented". Flipped classroom teaching model readjust the learning process of students. Students learn knowledge by using learning plans and video before class, and absorb and internalize knowledge through teacher-student and student-student exchanges in class[1]. The traditional mathematics classroom is dominated by teachers, and the forms of "one-word-class" and "full-class-filling" make the classroom boring. In addition, the difficult and complex content of high school mathematics causes students to lose interest in mathematics, let alone develop mathematical literacy and ability. Therefore, in the high school mathematics teaching, it is of great significance to change the traditional teaching mode and effectively introduce the flipped classroom teaching mode.

\section{CONNOTATION AND CHARACTERISTICS OF FLIPPED CLASSROOM}

The flipped classroom is also known as "upside-down classroom", which refers to the readjusting of time inside and outside the classroom to transfer the decision of learning from teachers to students [2]. Teachers no longer take up classroom time to impart knowledge, but let students learn independently by electronic devices before class, and use video, learning plans and other learning resources provided by teachers to preliminarily understand knowledge. In class, the teacher arranges the teaching according to the students' situation. With the help of the teacher, the students have an in-depth understanding of knowledge through exploration and discussion. The flipped classroom is a new teaching mode that fits the information age. It reconstructs students' learning process with the help of electronic devices, and effectively helps students learn new knowledge and absorb internalized knowledge. Compared with traditional classroom teaching, this new teaching mode has the following characteristics:

The learning style is more flexible. Traditional classroom teaching is to organize students to study in the same classroom, and the learning process is irreversible. The knowledge transfer process of flipped classroom relies on video teaching, which enables students to learn anytime and anywhere, no longer limited by time and space. When students have questions they don't understand, they can watch video repeatedly, or communicate and explore with their peers, so as to change passive learning into active exploration, stimulate students' interest in learning, and stimulate students' learning enthusiasm.

Focus on individual differences. The traditional classroom uses classroom time to transfer knowledge to students, teachers perform according to their own scripts, in the same time, teach the same knowledge to everyone, which leads to some students "not full", some students "can not eat". However, flipped classroom makes classroom contents closely centered on students through the new teaching mode of "learning before teaching, and internalization of knowledge in class". Teachers adjust classroom teaching according to students' conditions and play the role of "director", and truly take the student as the main body. In traditional classroom, teachers are eloquent on the platform and lack of interaction 
with students, while flipped classroom makes teachers step off the platform, walk among students, listen to students' ideas, pay attention to each student and conduct targeted teaching.

\section{The TeAChing Mode Of THE FlipPed ClassRoom}

Based on the cognitive structure and psychological characteristics of high school students, the flipped classroom can be summarized as the following teaching links:

\section{A. Pre-class knowledge transfer}

Pre-class knowledge transfer includes two parts, one is the teacher's preparation before class, and the other is the selfstudy before the class.

According to the requirements of high school mathematics curriculum standards and the overall learning situation of students, teachers should divide the teaching content into several parts reasonably and record video and customized learning plans according to each part.

Video is characterized by "short and concise". And video time had better be controlled within 10 minutes, which is in line with the scope of middle school students' attention to the duration intentionally, a long time will easily cause students to lose interest and reduce learning efficiency. And Video content should have a clear target, which is a miniaturized teaching process aiming at a certain knowledge point or specific problem[3]. And according to video content to develop the corresponding learning case, the main role of learning case is to guide and test. Through learning plans, teachers guide students to use learning resources to carry out effective independent learning and check students' selflearning. In particular, teachers should give full consideration to individual differences among students. And the development of the study should reflect the stratified teaching to meet the needs of students with different ability levels.

Students should arrange their own self-study time before class. Students who have a strong ability to receive the information can further expand their knowledge after watching the video, while students with weaker ability can watch the video repeatedly for multiple studies. At the same time, students should complete the learning plan content according to video explanation, find out their doubts and mark them on the learning plan, so as to facilitate teachers to conduct targeted explanation in class.

\section{B. Internalization of knowledge in class}

Through self-learning before class, a small number of students can master the knowledge, but most students have little knowledge of what they have learned. Therefore, teachers should give a targeted explanation of the content in the class according to the students' pre-class feedback. And the enthusiasm of students' learning is mobilized through group cooperation, so that students can internalize knowledge in the process of collaborative inquiry. Finally, teachers build a reasonable knowledge framework to deepen students' understanding of knowledge. In addition, teachers can also assign related exercises to check students' knowledge.

\section{Summary after class}

After class, teachers should guide students to summarize and review in a timely manner, further internalize the knowledge, reflect on the difficulties encountered in the whole learning process and overcome them in time. In addition, students can self-assess, group evaluation, teacher evaluation and other diversified methods for multi-angle evaluation, so that students can better understand themselves.

\section{THE PRACTICE OF THE FLIPPED ClASSROOM TEACHING MODE}

In order to verify the scientific and feasibility of flipped classroom teaching model in high school mathematics teaching, the author explores the "hyperbola and its standard equation "in the 2-1 high school mathematics textbook elective.

\section{A. Design and production of video and case content}

As an important pre-class tool of the flipped classroom, the selection and design of its content are extremely important. A good design is conducive to helping students to conduct scientific and effective independent learning.

TABLE I. PRE-CLASS TASK GUIDE

Subject name: hyperbola and its standard equation

Learning focus: Master the definition of the hyperbola and its standard equations

Learning difficulties: Master the standard equation of the hyperbola and derive the process

Learning tasks: Watch the micro-course video to complete the corresponding case content

Learning advice: Read the textbook, watch video, think carefully and explore analogies

Question: What doubts do you have from the above?

The first video reviews the definition of the ellipse and its standard equations in a questionable way. The problem is raised in the ellipse definition that the trajectory of a point whose distance from the two fixed points is a non-zero constant is an ellipse: If the sum is changed to difference, what is the trajectory of the point whose distance from the two fixed points is a non-zero constant? Ask the students to think and introduce the new lesson. Play the hyperbolic zipper simulation video; let the students find the moving point and the static point, and the equivalent relationship between the points. The analog ellipse definition defines the hyperbola. It is important to emphasize the existence of "absolute values" in the definition. 
TABLE II. SCHOOL CASE

\begin{tabular}{|c|l|l|}
\hline & \multicolumn{1}{|c|}{ Ellipse } & \multicolumn{1}{c|}{ Hyperbola } \\
\hline Definition & $\begin{array}{l}\text { The ellipse is the trajectory of the moving point } \mathrm{M} \text { in which the sum of } \\
\text { the distances between the two fixed points } \mathrm{F}_{1} \text { and } \mathrm{F}_{2} \text { is equal to a } \\
\left.\text { constant (greater than }\left|\mathrm{F}_{1} \mathrm{~F}_{2}\right|\right) \text {. The two fixed points are called the focal } \\
\text { points of the ellipse, and the distance between the two focal points is } \\
\text { called the focal length of the ellipse. }\end{array}$ & $\begin{array}{l}\text { The hyperbola is the trajectory of the moving point } \mathrm{M} \text { whose absolute } \\
\text { value of the difference between the distances between the two fixed } \\
\text { points } \mathrm{F}_{1} \text { and } \mathrm{F}_{2} \text { is equal to the constant }\left(\text { less than }\left|\mathrm{F}_{1} \mathrm{~F}_{2}\right|\right) \text {. The two } \\
\text { fixed points are called the focus of the hyperbola. The distance } \\
\text { between the two focal points is called double. The focal length of the } \\
\text { curve. }\end{array}$ \\
\hline $\begin{array}{c}\text { Normal } \\
\text { equation }\end{array}$ & $\quad\left|\mathrm{MF}_{1}\right|+\left|\mathrm{MF}_{2}\right|=2 a\left(2 a>\left|\mathrm{F}_{1} \mathrm{~F}_{2}\right|\right)$ & || $\mathrm{MF}_{1}|-| \mathrm{MF}_{2}||=2 a\left(2 a<\left|\mathrm{F}_{1} \mathrm{~F}_{2}\right|\right)$ \\
focus on $x$ axis: $\frac{x^{2}}{a^{2}}+\frac{y^{2}}{b^{2}}=1$ & focus on $y$ axis: $\frac{y^{2}}{a^{2}}+\frac{x^{2}}{b^{2}}=1$ & \\
\hline
\end{tabular}

The second video creates a hyperbolic standard equation analogous to the ellipse in a taught manner. By explaining the establishment process of standard equations, students are allowed to keep in mind the form of standard equations and feel the application of mathematical ideas of analogy and number combination in mathematics. The process of simplification is more complicated and needs to be explained in detail. Since the explanation content is to establish the standard equation with the focus on the $\mathrm{x}$ axis. Students should establish the standard equation with the focus on the y axis on the learning case by themselves, and hand in the calculation process to the teacher before class after the explanation.

The third video is mainly designed by students' independent inquiry and group discussion [4]. Through the examples of teaching materials, explain the application of the hyperbolic standard equations, so that students can not only learn the concept of analysis but also use the concept to solve mathematical problems.

TABLE III. SCHOOL CASE

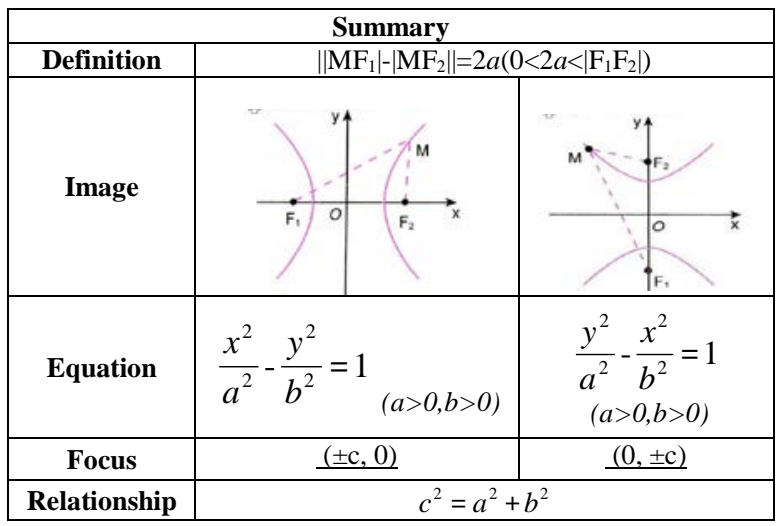

\section{B. Classroom teaching practice}

\section{a) Pre-class preparation}

Teachers must do a good job in full preparation before class, not only to prepare textbooks, but also prepare students, prepare teaching methods. The preparation of the teaching materials is to understand the teaching content and teaching difficulties of this lesson; the preparation students are familiar with the students' knowledge ability, in order to facilitate the construction of reasonable and appropriate "scaffolding". On this basis, it is necessary to make good videos and study cases, let students learn independently before class and ask questions according to self-study. Teachers should summarize students' feedback information in time and design classroom teaching according to the feedback information.

\section{b) Classroom teaching}

Internalization of knowledge is the main content of classroom teaching [5]. Show the hyperbolic pictures of life in class, and draw the distance between mathematics and real life. Then playback the hyperbolic zipper simulation video, so that students can recall the self-learning knowledge framework before class, summarizes the definition of hyperbola through group discussion. With the topic of "exploring the quantitative relationship between fixed points and moving points of hyperbola", group activities were carried out to further deepen students' understanding of the concept of hyperbola. And draw a conclusion and fill in the table.

TABLE IV. SCHOOL CASE

\begin{tabular}{|c|c|}
\hline $\begin{array}{c}\text { Quantitative } \\
\text { Relationship }\end{array}$ & trajectory \\
\hline $\begin{array}{c}\left|\mathrm{MF}_{1}\right|-\left|\mathrm{MF}_{2} \|=\right| \mathrm{F}_{1} \mathrm{~F}_{2} \mid \\
(2 a=2 \mathrm{c})\end{array}$ & $\begin{array}{r}\text { Two rays pointing outward on line } \mathrm{F}_{1}, \mathrm{~F}_{2} \text { and } \\
\text { ending at } \mathrm{F}_{1}, \mathrm{~F}_{2}\end{array}$ \\
\hline $\begin{array}{c}\left|\mathrm{MF}_{1}\right|-\left|\mathrm{MF}_{2} \|>\right| \mathrm{F}_{1} \mathrm{~F}_{2} \mid \\
(2 a>2 \mathrm{c})\end{array}$ & Non-existent \\
\hline $\begin{array}{c}\left|\mathrm{MF}_{1}\right|-\mid \mathrm{MF}_{2} \|=0 \\
(2 a=0)\end{array}$ & Perpendicular bisector of line segment $\mathrm{F}_{1}, \mathrm{~F}_{2}$ \\
\hline
\end{tabular}

After organizing students to learn the concept of hyperbola, they should strike while the iron is hot and further learn the understanding of the standard equation of a hyperbola. Through the feedback of students, the teacher projected several copies of the students' deduction process on the PPT, and mobilized the whole class to participate in error correction. Through a targeted explanation of the difficult points in the deduction process, the hyperbolic standard equations with focal points on the $\mathrm{x}$ and $\mathrm{y}$ axes are obtained. Compare the hyperbolic standard equations with focus on the $x$ and $y$ axes, find out the difference and relationship, and lead the students to summarize the hyperbolic standard equations (definition, image, focus, etc.). This will not only mobilize the students' enthusiasm for learning, but also enable students to develop a mathematical study habit that is summarized. In order to further consolidate the concepts learned and test the effect of the student self-study video three, students can be organized to explore the problem and further find problems and solve problems in the topic. 
Finally, the teacher summarizes the content of this lesson by organizing and guiding the students to talk about the learning and learning, helping students form the knowledge structure, summarizing the problems encountered before and during the class, and solving the problems in time.

\section{c) Summary after class}

After class, students are guided to comprehensively review, analyze, summarize and evaluate the process of independent learning and the level of class participation, so as to promote the integration and internalization of self-knowledge and the formation of good learning habits [6].

\section{SUMMARY}

In short, under the background of "Internet +", the introduction of flipped classroom teaching mode into high school mathematics class not only meets the requirements of current education reform, but also helps stimulate students' interest in mathematics and promote their comprehensive development. Therefore, teachers should use flipped classroom teaching mode reasonably and effectively, transfer knowledge before class, internalize knowledge in class and reflect and summarize after class, give full play to the advantages of flipped classroom teaching mode, enrich classroom teaching activities, improve the quality of mathematics teaching, and enhance students' mathematical learning ability.

\section{REFERENCES}

[1] Zhao xinglong. The Design of Teaching Mode Based on Knowledge Construction in Flipped Classroom [J]. Modern Distance Education Research, 2014(02):55-61. (In Chinese)

[2] Zou Gaoyun. The Effectiveness of Introducing the Flipped Classroom Mode in Middle School Physics Teaching [J]. References for Middle School Physics Teaching, 2018, 47(16): 4-5. (In Chinese)

[3] Xu Shiqing. The Design of High School Mathematics Teaching Based on Flipping Classroom-Taking the Teaching of Several Kinds of Different Growth Function Models as an Example [J]. Mathematics Teaching Communication, 2018(30): 22-23. (In Chinese)

[4] Song Lei, Li Qiang. Flipped the Classroom: Let the students' mathematics literacy to the core "diffractive" - taking the Su Ke version of "the inner angle of the polygon" as an example [J]. Mathematics Teaching Communication, 2018 (20): 16-17. (In Chinese)

[5] Miao Qiang. Analysis of junior high school mathematics flip classroom teaching based on micro-course[J].China Educational Technology and Equipment,2018(15):96-98.M.Young,The Technical Writer's Handbook. Mill Valley, CA: University Science, 1989. (In Chinese)

[6] Zhang Zhiyue. Exploring the Effectiveness of Introducing the Classroom Teaching Mode into High School Mathematics Teaching-Taking the Position Relationship of Straight Line and Circle as an Example[J]. Mathematics Teaching Communication, 2018(24): 29-30. (In Chinese) 